\title{
A Fiber Optic Temperature Sensor Based on the Combination of Epoxy and Glass Particles With Different Thermo-Optic Coefficients
}

\author{
Wolfgang WILDNER ${ }^{*}$ and Dietmar DRUMMER \\ Institute of Polymer Technology, Friedrich-Alexander-University Erlangen-Nürnberg, Erlangen, Germany \\ *Corresponding author: Wolfgang WILDNERＥ-mail: wildner@lkt.uni-erlangen.de
}

\begin{abstract}
This paper describes the development and function of an optical fiber temperature sensor made out of a compound of epoxy and optical glass particles. Because of the different thermo-optic coefficients of these materials, this compound exhibits a strong wavelength and temperature dependent optical transmission, and it therefore can be employed for fiber optic temperature measurements. The temperature at the sensor, which is integrated into a polymer optical fiber (POF), is evaluated by the ratio of the transmitted intensity of two different light-emitting diodes (LED) with a wavelength of $460 \mathrm{~nm}$ and $650 \mathrm{~nm}$. The material characterization and influences of different sensor lengths and two particle sizes on the measurement result are discussed. The temperature dependency of the transmission increases with smaller particles and with increasing sensor length. With glass particles with a diameter of $43 \mu \mathrm{m}$ and a sensor length of $9.8 \mathrm{~mm}$, the intensity ratio of the two LEDs decreases by $60 \%$ within a temperature change from $10^{\circ} \mathrm{C}$ to $40^{\circ} \mathrm{C}$.
\end{abstract}

Keywords: Temperature sensors; fiber optic sensors; epoxy; glass particles; thermo-optic coefficient

Citation: Wolfgang WILDNER and Dietmar DRUMMER, "A Fiber Optic Temperature Sensor Based on the Combination of Epoxy and Glass Particles With Different Thermo-Optic Coefficients," Photonic Sensors, 2016, 6(4): 295-302.

\section{Introduction}

Fiber optic temperature sensing enables monitoring in particular surroundings such as microwaves or explosion sensitivity [1-4]. Commercially, available fiber optic temperature sensors often use a semiconductor-chip, which has an absorption edge that moves with the temperature $[5,6]$. Other sensors utilize Bragg gratings [7-9] or the temperature-dependent fluorescence intensity of certain materials [10] to measure the temperature. Another way is to analyze the Raman scattering in a glass fiber [11] or to analyze the temperature with a Fabry-Pérot interferometer (FPI) [12, 13] or with a Mach-Zehnder interferometer [14] integrated into an optic fiber. Also stimulated Brillouin scattering can be used for distributed temperature measurement [15, 16] whereby the scattered frequency depends on the temperature of the fiber.

Most temperature sensing applications use glass fibers for information transport and measurement. Nevertheless, the use of a polymer optical fiber (POF) has several advantages: POFs have low costs, high elastic strain limits, and high fracture toughness, [17] which enable sensing in deforming structures [18] amongst others.

Glass-filled polymers have a large field of applications in a wide variety of polymer parts. Glass as a filler is used to enhance the mechanical properties [19], to reduce the thermal expansion [20,

Received: 21 April 2016 / Revised: 18 August 2016

(C) The Author(s) 2016. This article is published with open access at Springerlink.com

DOI: $10.1007 / \mathrm{s} 13320-016-0328-6$

Article type: Regular 
21] or to cause light scattering in backlight units of displays [22, 23].

Applied in transparent polymers, glass fillers with a similar refractive index (RI) to the polymer generally cause a RI difference dependent transmission [24-26]. The RI difference of a single material changes with the wavelength of the incident light (dispersion) and with the temperature (thermo-optic coefficient). The thermo-optic coefficient $\Delta n_{\text {rel }} / \Delta T$ of optical glass has a value between $-5.4 \cdot 10^{-6} \mathrm{~K}^{-1}$ and $32.2 \cdot 10^{-6} \mathrm{~K}^{-1}$ [27], while polymers have a negative thermo-optic coefficient, which is nearly two orders of magnitude higher [28]. This paper shows fiber optic temperature measurement with a compound comprised of glass particles and epoxy. The different thermo-optic coefficients and dispersions of the utilized glass particles and polymer cause a high temperature dependence of the transmission. The first experiments of this measuring principle with oil as the matrix have been reported before [29]. The described fiber-optic sensor is very compact in size and has the potential for low-cost production. It also enables the temperature evaluation by intensity measurements, therefore no spectrometer is needed.

\section{Methodology}

\subsection{Sample preparation}

For the investigations described in this paper, the transparent epoxy SpeciFix40 (Struers) was chosen as the matrix because of the high transparency and low shrinkage along with glass particles (N-BAK1, Schott) as the filler material. The SpeciFix40 system consisted of the resin and a curing agent which contains 3-aminomethyl-3,5,5-trimethylcyclohexylamine and benzyl alcohol. The RI of the glass was calculated with the Sellmeier Equation using the Sellmeier coefficients given from the manufacturer:

$$
n(\lambda)=\sqrt{1+\frac{B_{1} \lambda^{2}}{\lambda^{2}-C_{1}}+\frac{B_{2} \lambda^{2}}{\lambda^{2}-C_{2}}+\frac{B_{2} \lambda^{2}}{\lambda^{2}-C_{3}}}
$$

where $B_{i}$ and $C_{i}$ are the Sellmeier coefficients, and $\lambda$ is the wavelength in $\mu \mathrm{m}$.

This glass was selected for its matching RI with the polymer matrix in the visible range which is necessary for the RI measurements described later. Table 1 summarizes some relevant properties of the employed glass and polymer.

The bulk glass was crushed and then sieved to produce particles in two different size ranges. The therefore employed two laboratory sieves have mesh widths of $63 \mu \mathrm{m}$ and $90 \mu \mathrm{m}$. The resulting particles vary between $0-63 \mu \mathrm{m}$ and $63 \mu \mathrm{m}-90 \mu \mathrm{m}$. Afterwards, the glass particles, sieved with a mesh width between $63 \mu \mathrm{m}$ and $90 \mu \mathrm{m}$, were washed in a supersonic bath to remove any residual dust particles.

Table 1 Relevant properties of the epoxy and glass.

\begin{tabular}{|c|c|c|}
\hline Material property & $\begin{array}{c}\text { Epoxy: } \\
\text { Specifix } 40\end{array}$ & Glass: N-BAK1 \\
\hline Density $\left(\mathrm{g} / \mathrm{cm}^{3}\right)$ & $1.1^{(1)}$ & $3.19^{(1)}$ \\
\hline $\begin{array}{c}\text { Total Transmission } \\
(\%)\end{array}$ & $91.28^{(2)}$ & $\begin{array}{l}\text { internal transmittance at } 546 \mathrm{~nm} \\
(10 \mathrm{~mm}): 99.8^{(1)}\end{array}$ \\
\hline $\begin{array}{l}\text { Coefficient of thermal } \\
\text { expansion }[\mu \mathrm{m} /(\mathrm{mK})]\end{array}$ & $\begin{array}{c}77.9 \\
\left(-10 /+40^{\circ} \mathrm{C}\right)^{(3)}\end{array}$ & $\begin{array}{c}7.6 \\
\left(-30 /+70^{\circ} \mathrm{C}\right)^{(1)}\end{array}$ \\
\hline $\begin{array}{l}\text { Thermo-optic } \\
\text { coefficient }\left(\mathrm{K}^{-1}\right)\end{array}$ & $-1.51 \cdot 10^{-4(4)}$ & $1.2 \cdot 10^{-6}\left(546 \underset{(1)}{\mathrm{nm}},+20 /+40^{\circ} \mathrm{C}\right)$ \\
\hline $\begin{array}{c}\mathrm{RI} n_{\mathrm{D}}\left(20^{\circ} \mathrm{C}\right) \\
(-)\end{array}$ & $\begin{array}{l}1.573^{(1)} \\
1.569^{(4)}\end{array}$ & $1.57250^{(1)}$ \\
\hline
\end{tabular}

(1) Manufacturer information;

(2) Spectrometer measurement with integrating sphere at $589 \mathrm{~nm}$, sample thickness: $1 \mathrm{~mm}$;

(3) TMA measurement;

(4) Measurement: see results section.

The sensor elements for temperature measurements were prepared via casting of the particle filled polymer in silicone molds. In order to obtain a high filling degree, the resin and curing agent in a ratio of 2.5 to 1 by weight and glass particles were mixed together in a test tube. Then it was waited for 30 minutes to let the particles settle down at the bottom of the tube. From there the mixture was filled into the silicone mold. A section of a polished POF (Hitronic POF Simplex) was attached to each end of the sensor element to connect the sensor to the light guides (Hitronic POF Simplex) during temperature sensing afterwards. 
Figure 1 shows a cross section of the mold with the attached fiber sections and the completed sensor element. After the casting, the polymer was cured in the mold for 24 hours at room temperature and then cured for 3.5 hours at $50^{\circ} \mathrm{C}$ in an oven. A list of the different produced sensor elements is given in Table 2.

An unfilled specimen (resin and curing agent) with a size of $50 \mathrm{~mm} \times 10 \mathrm{~mm} \times 10 \mathrm{~mm}$ was casted following the same curing procedure. This one was used for the measurement of the polymer's RI with the Abbe refractometer.
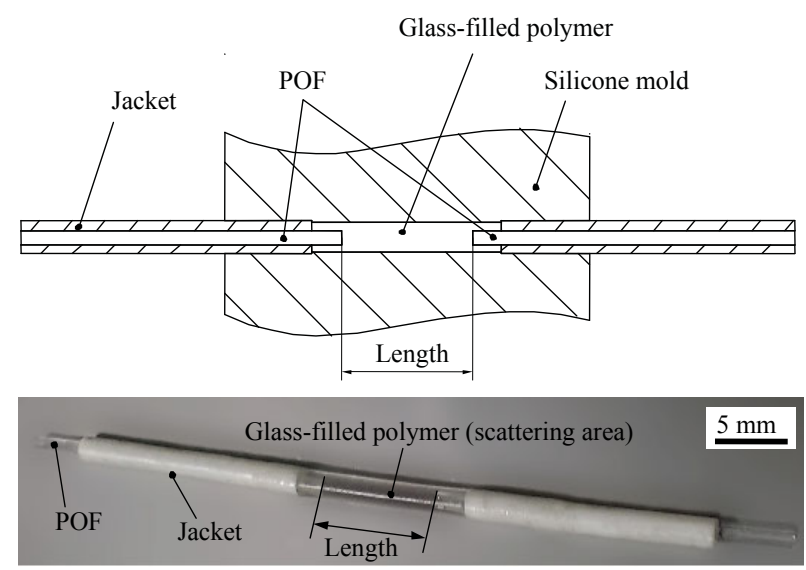

Fig. 1 Molding of the sensor elements (above) and completed sensor element with attached fibers and scattering area (glass-filled polymer).

Table 2 Produced sensor elements.

\begin{tabular}{cc}
\hline Particle size (sieving) $(\mu \mathrm{m})$ & Length $(\mathrm{mm})$ \\
\hline \multirow{2}{*}{$0-63$} & 4.1 \\
& 7.3 \\
& 9.8 \\
\multirow{2}{*}{$63-90$} & 3.5 \\
& 7.4 \\
\hline
\end{tabular}

\subsection{Sample characterization}

The filling degree of the sensor elements was determined with TGA measurements (TGA Q 5000, TA instruments). Within the TGA measurement, the sample was heated up to $800^{\circ} \mathrm{C}$ in an oxygen atmosphere while measuring the weight. By the end of the heating, the polymer had evaporated completely, as unfilled specimens have shown before. The weight portion of the remaining glass particles was converted into the percentage of glass particles by volume.
The volumetric particle-distribution was determined by the measuring instrument "Morphologi G3" of Malvern instruments.

The RI $n_{\mathrm{D}}$ (wavelength: $589 \mathrm{~nm}$ ) of the polymer at different temperatures was analyzed with the Abbe-Refractometer AR2008 (Kruess) at the therefore prepared unfilled specimen. A thermostat was used to induce different temperatures $\left(10^{\circ} \mathrm{C}\right.$, $20^{\circ} \mathrm{C}$, and $40^{\circ} \mathrm{C}$ ) at the refractometer, and bromine naphthalene was applied as a contact liquid. The polymer's thermo-optic coefficient was calculated from its change in $n_{D}$ with the temperature.

The polymer's RI with respect to the wavelength was determined by transmission measurements through the longest sensor element:

A matching RI between the filler and matrix leads to a maximum transmission. Therefore, the transmission of three LEDs $(460 \mathrm{~nm}, 520 \mathrm{~nm}$, and $595 \mathrm{~nm}$ ) was analyzed by measuring the transmitted light intensity with a PIN-photodiode. The temperature at the sensor element was varied between $-15^{\circ} \mathrm{C}$ and $60^{\circ} \mathrm{C}$ during each measurement. The result was the temperature of a maximum transmission at each of the three wavelengths corresponding to a matching RI between the filler and matrix. With the given glass' RI and the polymer's thermo-optic coefficient, the polymer's RI at $20{ }^{\circ} \mathrm{C}$ was calculated for these three wavelengths. The polymer's RI in the range between $350 \mathrm{~nm}$ and $750 \mathrm{~nm}$ was approximated with Cauchy's equation afterwards:

$$
n(\lambda)=A \frac{B}{\lambda^{2}}+\frac{C}{\lambda^{4}} .
$$

The schematic setup for the fiber optic temperature measurements is given in Fig. 2. The light of two pigtail-LEDs with wavelengths of $460 \mathrm{~nm}$ and $650 \mathrm{~nm}$ was guided through a splitter and a POF to the sensor element. The transmitted light by the sensor element was guided through another POF to a PIN-photodiode (Diemount Gmbh). The software DASYLAB with the measurement device DAQ3000 was employed to operate the 
LEDs. A constant voltage of $5 \mathrm{~V}$ was applied in the reverse direction at the PIN-photodiode. The instrument Nanovoltmeter (Keithley) was used to measure the voltage signal $U_{M}$ at a resistor of $10 \mathrm{k} \Omega$ in series with the PIN-photodiode.

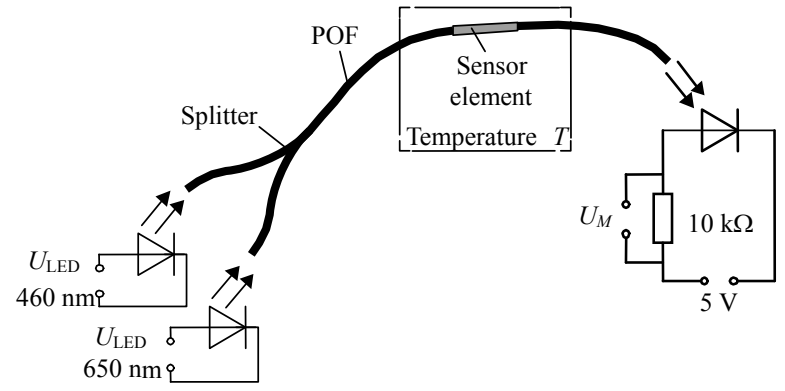

Fig. 2 Schematic measurement setup for fiber optic temperature measurements.

The voltage $U_{M}$ linearly depends on the reverse current of the PIN-photodiode which itself is a linear function of the incident light. The LEDs were operated one after another for 3.3 seconds each. For another 3.3 seconds, the ambient light was collected while the LEDs were switched off. Consequently, about every 10 seconds three voltage values were collected: one for each wavelength and one for the ambient light.

\section{Results and discussion}

\subsection{Material properties}

The average filling degree of the sensor elements is 30.5 vol.- $\% \pm 4.3$ vol.- $\%$ glass particles. The particles sieved between 0 and $63 \mu \mathrm{m}$ have a size of $d_{50.3}=43 \mu \mathrm{m}\left(d_{10.3}=18 \mu \mathrm{m}\right.$ and $\left.d_{90.3}=70 \mu \mathrm{m}\right)$ and the particles sieved between $63 \mu \mathrm{m}$ and $90 \mu \mathrm{m}$ have a size of $d_{50.3}=83 \mu \mathrm{m}\left(d_{10.3}=27 \mu \mathrm{m}\right.$ and $\left.d_{90.3}=138 \mu \mathrm{m}\right)$. The sensor element's maximum transmission of the three LEDs, which have been utilized for RI measurements, is located at a temperature of $-6.5^{\circ} \mathrm{C}$ $(460 \mathrm{~nm}), 14.9^{\circ} \mathrm{C}(520 \mathrm{~nm})$, and $43.6^{\circ} \mathrm{C}(595 \mathrm{~nm})$, as shown in Fig. 3. The polymer's wavelength dependent RI at $20^{\circ} \mathrm{C}$ is calculated out of these three points of a matching RI. The Cauchy coefficients for the RI at $20{ }^{\circ} \mathrm{C}$ are: $A=1.546$, $B=7.001 \cdot 10^{-3}$, and $C=2.895 \cdot 10^{-4}$, as shown in Fig. 4 (a).

The RI of the polymer declines almost linearly with increasing temperature in the analyzed range, as shown by refractometer measurements in Fig. 4(b). The value of the calculated average thermo-optic coefficient is $-1.51 \cdot 10^{-4} \mathrm{~K}^{-1}$, of which the absolute value is two magnitudes higher than the glass' one.

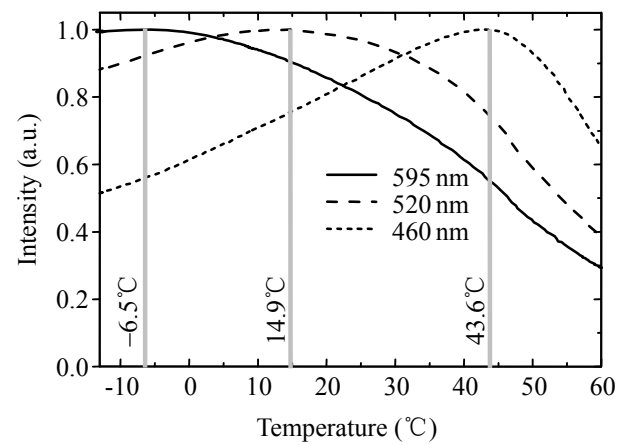

Fig. 3 Temperature dependent transmission for $460 \mathrm{~nm}$, $520 \mathrm{~nm}$, and $595 \mathrm{~nm}$ of a sensor element (particles: $d_{50.3}=43 \mu \mathrm{m}$; length: $9.8 \mathrm{~mm}$ ).

The RI of the polymer as given by the manufacturer lies above the measured values. Also the values determined with the refractometer lie slightly above the values analyzed by transmission measurements [Fig. 4(b)].
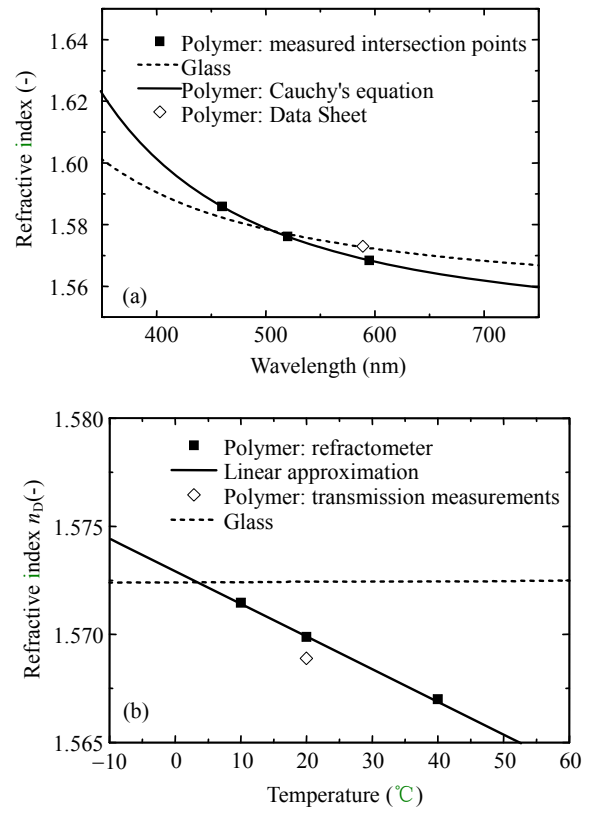

Fig. 4 RI of polymer and glass in dependence of (a) the wavelength at $20^{\circ} \mathrm{C}$ and (b) temperature at $589 \mathrm{~nm}$.

Reasons therefore may be the different thicknesses of the specimens which influence the 
temperature during curing, and therefore, the curing properties [30, 31].

Figure 5 shows the temperature and the voltage $U_{M}$ (for a wavelength of $460 \mathrm{~nm}$ and $650 \mathrm{~nm}$ ) with respect to the time for sensor elements with different lengths and a particle size of $d_{50.3}=43 \mu \mathrm{m}$. The change in the voltage per temperature increases for the two wavelengths with the length of the sensor element.

The percentage change in the intensity (voltage at $10^{\circ} \mathrm{C}=100 \%$ ) was evaluated for different sensor lengths and two different particle sizes in Fig. 6. This result shows that longer sensors and smaller particles increase the dependency on the temperature. This is meant to be caused by the consequential larger scattering interface between the particles and the matrix [24, 32].

Figure 7(a) shows the temperature dependent voltage ratio (corresponding to the intensity ratio at the photodiode) of the sensor elements with a particle size of $d_{50.3}=43 \mu \mathrm{m}$. The curves' slope increases with the length of the sensor elements due to the reasons described above. Additionally, the experiments show that the material combination almost exhibits a linear behavior of the intensity ratio in the investigated temperature range from $10^{\circ} \mathrm{C}$ to $40^{\circ} \mathrm{C}$.

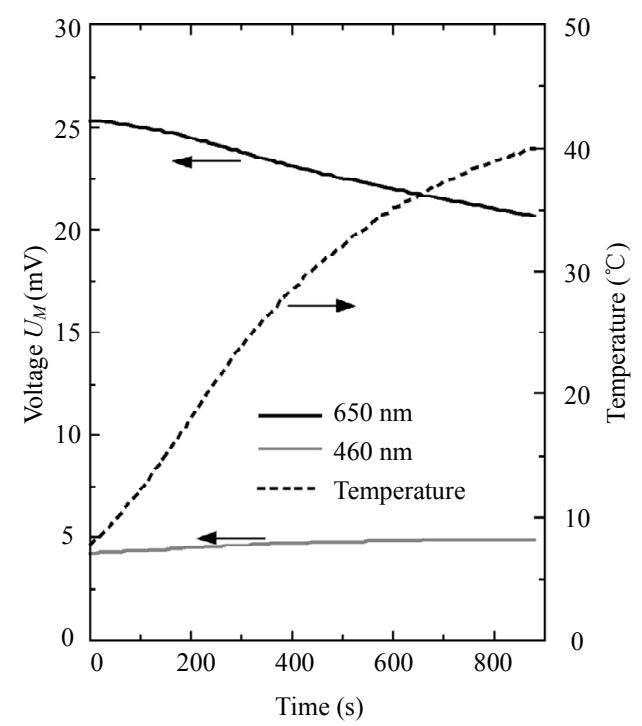

(a)

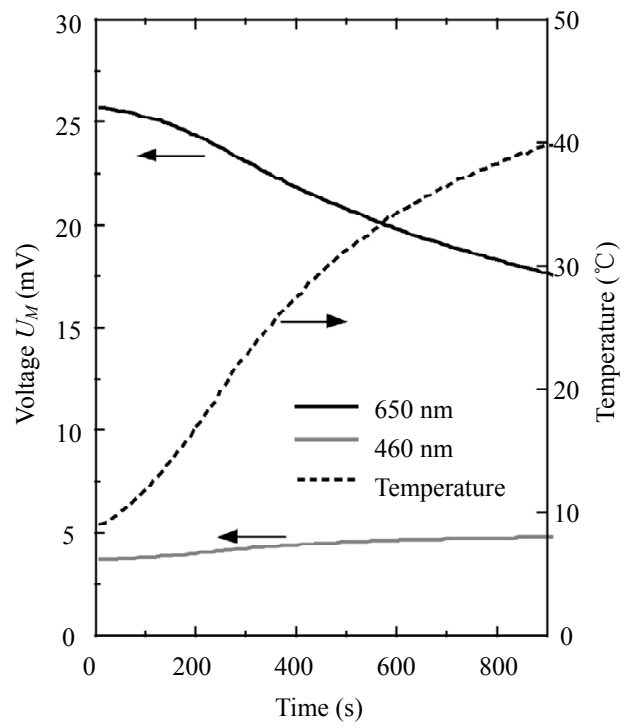

(b)

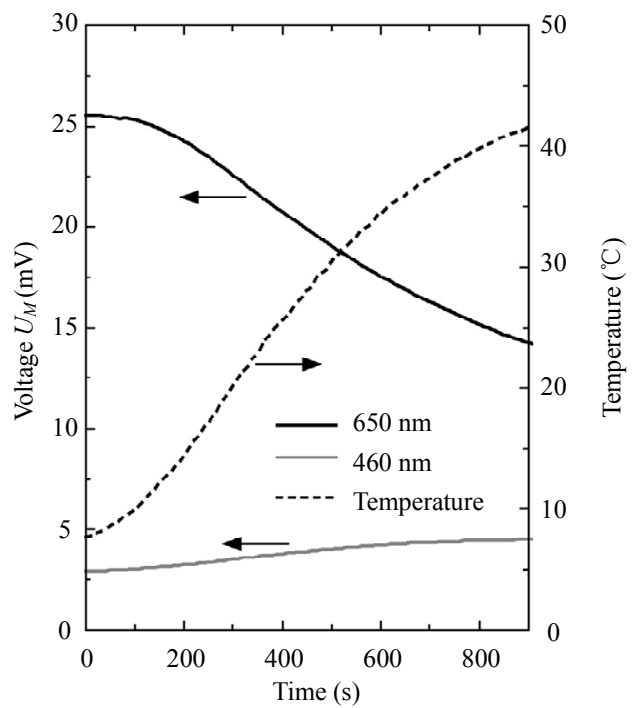

(c)

Fig. 5 Temperature and voltage at the photodiode for three different sensor elements with a particle size of $d_{50.3}=43 \mu \mathrm{m}$; length from (a) $4.1 \mathrm{~mm}$, (b) $7.3 \mathrm{~mm}$, and (c) $9.8 \mathrm{~mm}$.

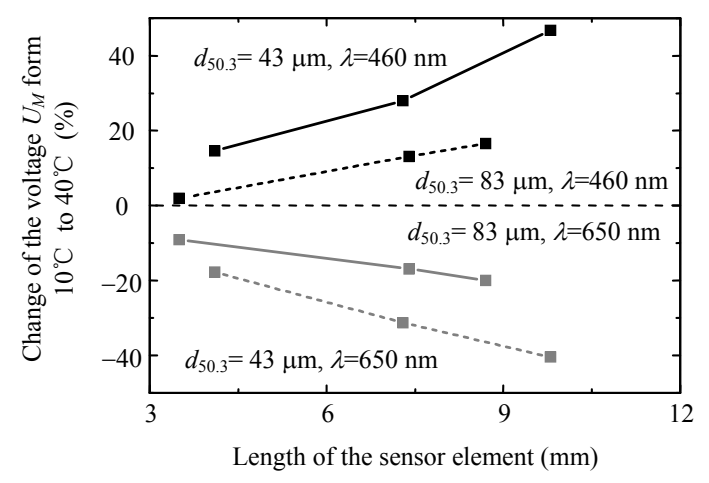

Fig. 6 Percentage change in the intensity for different sensor elements during the heating between $10^{\circ} \mathrm{C}$ and $40^{\circ} \mathrm{C}$ with regard to the intensity at a temperature of $10^{\circ} \mathrm{C}$. 


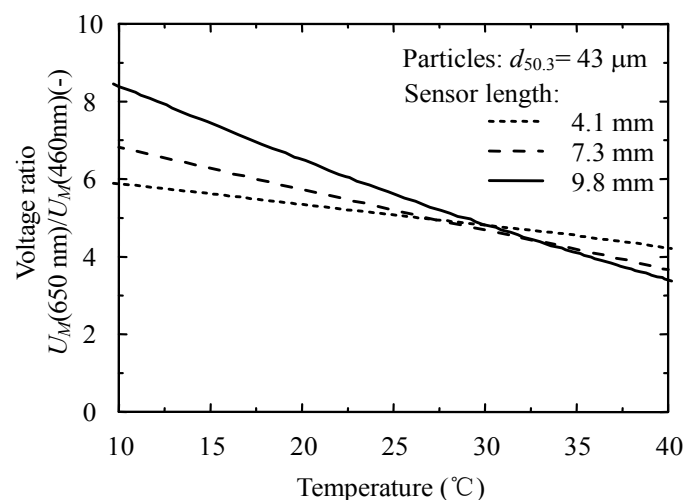

(a)

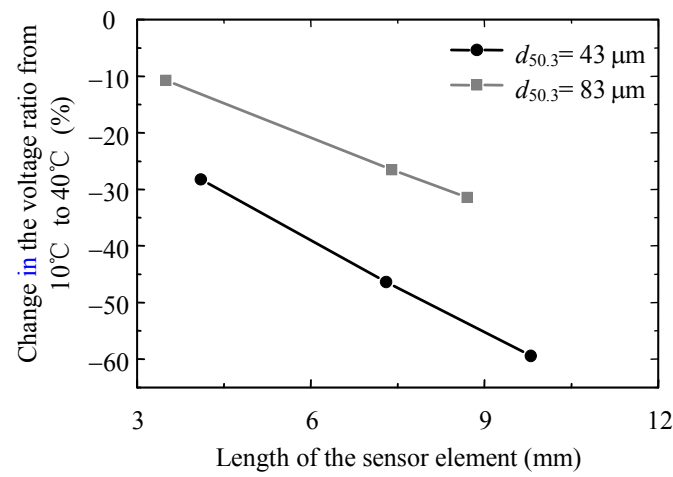

(b)

Fig. 7 Voltage ratio for different sensor lengths with a particle size of $d_{50.3}=43 \mu \mathrm{m}$ (a) and percentage change in the voltage ratio for different sensor elements between $10^{\circ} \mathrm{C}$ and $40^{\circ} \mathrm{C}$ (b).

The sensor element with a length of $9.8 \mathrm{~mm}$ and particle size of $d_{50.3}=43 \mu \mathrm{m}$ shows the strongest decline in the intensity ratio of $-60 \%$ for a temperature change of $30{ }^{\circ} \mathrm{C} \quad$ (Fig. 7(b)). In comparison, the transmitted intensity of a sensor based on thermochromic material increases by $41 \%$ between 0 and $30^{\circ} \mathrm{C}$ [33]. The intensity ratio of the Stokes line to the anti-Stokes line of a typical temperature Raman sensor increases by about $10 \%$ ( 0.28 to 0.31 ), the Brillouin frequency (Brillouin sensor) increases about $0.3 \%(12.78 \mathrm{GHz}$ to 12.82 $\mathrm{GHz}$ ) and the Bragg wavelength of a typical Fiber Bragg Grating sensor increases by $0.02 \%(832.64$ $\mathrm{nm}$ to $832.81 \mathrm{~nm}$ ) with a temperature shift from 0 to $30^{\circ} \mathrm{C}$ [34].

Consequently, in order to build a high resolution sensor it is useful to employ materials with strong differences in the thermo-optic coefficients. As shown above, also small fillers and long scattering distances lead to more accurate measurements.
Nevertheless, potential negative influences on the transmission have to be taken into account. Several heating and cooling cycles may cause debonding of the particles and the matrix due to thermal stresses which might reduce the overall transmission. Also other disturbing influences on the measuring result, like yellowing because of the polymer's aging or RI changes because of the absorption of water or chemicals, have to be respected.

\section{Conclusions}

This paper shows the implementation of a fiber optic temperature sensor based on different thermo-optic coefficients of a polymer and glass particles. The wavelength dependent RI of the polymer was determined by the analyzation of the materials' matching RI, which led to a maximum transmission of the compound. The influences of the sensor length and two different particle sizes on the temperature measurement are described in the paper, whereas small particles and long sensor elements increase the temperature dependent scattering and therefore the sensor's potential accessible accuracy. With a particle size of $d_{50.3}=43 \mu \mathrm{m}$ and a sensor length of $9.8 \mathrm{~mm}$, the intensity ratio of the two applied LEDs decreases by $60 \%$ within a temperature change of $30{ }^{\circ} \mathrm{C}$.

\section{Acknowledgment}

The authors would like to acknowledge the funding of the Deutsche Forschungsgemeinschaft (DFG) through the Cluster of Excellence Engineering of Advanced Materials and to thank Dr.-Ing. H. Kragl of Diemount GmbH for his help with the measurement setup.

Open Access This article is distributed under the terms of the Creative Commons Attribution 4.0 International License (http://creativecommons.org/licenses/by/4.0/), which permits unrestricted use, distribution, and reproduction in any medium, provided you give appropriate credit to the original author(s) and the source, provide a link to the Creative Commons license, and indicate if changes were made. 


\section{References}

[1] B. Lee, "Review of the present status of optical fiber sensors," Optical Fiber Technology, 2003, 9(2): 57-79.

[2] V. I. Busurin, A. S. Semenov, and N. P. Udalov, "Optical and fiber-optic sensors (review)," Soviet Journal of Quantum Electronics, 1985, 15(5): 595-621.

[3] K. T. V. Grattan and T. Sun, "Fiber optic sensor technology: an overview," Sensors and Actuators, A: Physical, 2000, 82(1): 40-61.

[4] A. D. Kersey, "A review of recent developments in fiber optic sensor technology," Optical Fiber Technology, 1996, 2(3): 291-317.

[5] C. Renschen, "Fi(e)be-thermometer, Prinzipien und Anwendungen der faseroptischen Temperaturemessung," Laser+Photonik, 2004, 3(4): 38-40.

[6] K. Kyuma, S. Tai, T. Sawada, and M. Nunoshita, "Fiber-optic instrument for temperature measurement," IEEE Journal of Quantum Electronics, 1982, 18(4): 676-679.

[7] Y. J. Rao, "In-fiber Bragg grating sensors," Measurement Science and Technology, 1997, 8(4): 355-375.

[8] A. D. Kersey, M. A. Davis, H. J. Patrick, M. LeBlanc, K. P. Koo, C. G. Askins, et al., "Fiber grating sensors," Journal of Lightwave Technology, 1997, 15(8): 1442-1462.

[9] J. Mandal, S. Pal, T. Sun, K. T. V. Grattan, A. T. Augousti, and S. A. Wade, "Bragg grating-based fiber-optic laser probe for temperature sensing," IEEE Photonics Technology Letters, 2004, 16(1): 218-220.

[10] E. Maurice, G. Monnom, B. Dussardier, A. Saissy, D. B. Ostrowsky, and G. W. Baxter, "Erbium-doped silica fibers for intrinsic fiber-optic temperature sensors," Applied Optics, 1995, 34(34): 8019-8025.

[11] D. Samiec, "Verteilte faseroptische Temperatur- und Dehnungsmessung mit sehr hoher Ortsauflösung," Photonik, 2011, 43(6): 34-37.

[12] W. H. Tsai and C. J. Lin, "A novel structure for the intrinsic Fabry-Perot fiber-optic temperature sensor," Journal of Lightwave Technology, 2001, 19(5): 682-686.

[13] C. Wu, H. Y. Fu, K. K. Qureshi, B. O. Guan, and H. Y. Tam, "High-pressure and high-temperature characteristics of a Fabry-Perot interferometer based on photonic crystal fiber," Optics Letters, 2011, 36(3): 412-414.

[14] Y. Wang, Y. Li, C. Liao, D. N. Wang, M. Yang, and P. $\mathrm{Lu}$, "High-temperature sensing using miniaturized fiber in-line Mach-Zehnder interferometer," IEEE Photonics Technology Letters, 2010, 22(1): 39-41.
[15] D. Culverhouse, F. Farahi, C. N. Pannell, and D. A. Jackson, "Potential of stimulated Brillouin scattering as sensing mechanism for distributed temperature sensors," Electronics Letters, 1989, 25(14): 913-915.

[16] X. Bao and L. Chen, "Recent progress in Brillouin scattering based fiber sensors," Sensors, 2011, 11(4): 4152-4187.

[17] K. Peters, "Polymer optical fiber sensors - a review," Smart Materials and Structures, 2011, 20(1): 13002-17.

[18] W. R. Habel and K. Krebber, "Fiber-optic sensor applications in civil and geotechnical engineering," Photonic Sensors, 2011, 1(3): 268-280.

[19] B. D. Agarwal, L. J. Broutman, and K. Chandrashekhara, Analysis and performance of fiber composites. New York: Wiley, 2006.

[20] K. C. Yung, B. L. Zhu, T. M. Yue, and C. S. Xie, "Preparation and properties of hollow glass microsphere-filled epoxy-matrix composites," Composites Science and Technology, 2009, 69(2): 260-264.

[21] A. Chandra, W. H. Meyer, A. Best, A. Hanewald, and G. Wegner, "Modifying thermal expansion of polymer composites by blending with a negative thermal expansion material," Macromolecular Materials and Engineering, 2007, 292(3): 295-301.

[22] H. Q. Tang, Z. F. Tang, T. T. Zhao, W. L. Li, and Q. Ye, "Preparation and optical properties of polysiloxane microspheres/PMMA light scattering materials," Guangzi Xuebao/Acta Photonica Sinica, 2012, 41(6): 723-727.

[23] Y. Zhao, P. Ding, C. Ba, A. Tang, N. Song, and Y. Liu, "Preparation of $\mathrm{TiO}_{2}$ coated silicate micro-spheres for enhancing the light diffusion property of polycarbonate composites," Displays, 2014, 35(4): 220-226.

[24] W. Wildner and D. Drummer, "Modelling haze and transmission of transparent filled systems in dependence of filler surface area, refractive index difference and wavelength," in SPE ANTEC ${ }^{\mathrm{TM}}$ Orlando, USA, 2015.

[25] W. Wildner and D. Drummer, "Wavelength dependent haze of transparent glass-particle filled poly(methyl methacrylate) composites," International Scholarly Research Notice, 2014, 2014: $1-5$.

[26] H. Breuer and J. Grzesitza, “Trübungserscheinungen in zweiphasigen Polymersystemen (glasfaserverstarkte Polymere)," Die Angewandte Makromolekulare Chemie, 1975, 45(681): 1-19.

[27] Optisches Glas: Datenblätter: Schott AG, 2012.

[28] J. Graf, Entwicklung und Untersuchungen zur Herstellung verlustarmer passiver Wellenleiter und 
verstärkender Wellenleiter, Ph.D. dissertation, Universität des Saarlandes, Saarbrücken, Germany, 1999.

[29] W. Wildner and D. Drummer, "A fiber optic temperature sensor based on the combination of two materials with different thermo-optic coefficients," IEEE Sensors Journal, 2015, 16(3): 688-692.

[30] A. C. Loos and G. S. Springer, "Curing of epoxy matrix composites," Journal of Composite Materials, 1983, 17(2): 135-169.

[31] J. H. Oh and D. G. Lee, "Cure cycle for thick glass/epoxy composite laminates," Journal of Composite Materials, 2002, 36(1): 19-45.
[32] T. Naganuma and Y. Kagawa, "Effect of total particle surface area on the light transmittance of glass particle-dispersed epoxy matrix optical composites," Journal of Materials Research, 2002, 17(12): 3237-3241.

[33]N. Díaz-Herrera, M. C. Navarrete, O. Esteban, and A. González-Cano, "A fiber-optic temperature sensor based on the deposition of a thermochromic material on an adiabatic taper," Measurement Science and Technology, 2004, 15(2): 353-358.

[34] F. Bernhard, Handbuch der technischen Temperaturmessung. Berlin Heidelberg: Springer, 2014. 